\title{
Article
}

\section{Evaluation of Shear Effect on Deflection of RC Beams}

\author{
Sang-Woo Kim ${ }^{1}\left(\mathbb{D}\right.$, Dong-Seok Han ${ }^{2}$ (D) and Kil-Hee Kim ${ }^{2, *(\mathbb{D})}$ \\ 1 Department of Civil, Architectural and Environmental System Engineering Graduate School, \\ Sungkyunkwan University, Suwon 16419, Korea; swkim91@skku.edu \\ 2 Department of Architectural Engineering \& Urban System Engineering, Kongju National University, \\ Cheonan 31080, Korea; hands8602@naver.com \\ * Correspondence: kimkh@kongju.ac.kr
}

check for updates

Citation: Kim, S.-W.; Han, D.-S.; Kim, K.-H. Evaluation of Shear Effect on Deflection of RC Beams. Appl. Sci. 2021, 11, 7690. https://doi.org/ 10.3390/app11167690

Academic Editors: Chiara Bedon, Kang Su Kim and Myoungsu (James) Shin

Received: 12 July 2021

Accepted: 19 August 2021

Published: 21 August 2021

Publisher's Note: MDPI stays neutral with regard to jurisdictional claims in published maps and institutional affiliations.

Copyright: (C) 2021 by the authors. Licensee MDPI, Basel, Switzerland. This article is an open access article distributed under the terms and conditions of the Creative Commons Attribution (CC BY) license (https:// creativecommons.org/licenses/by/ $4.0 /)$.

\begin{abstract}
This study evaluates the effect of shear on the deflection of reinforced concrete (RC) beams subjected to combined bending and shear. A total of nine simply supported beams were manufactured with the shear span-to-depth ratio, tension steel ratio, and shear capacity ratio as test variables. The experimental results were used to evaluate the effect of shear on the deflection by separating them into flexural and shear deformations. The theoretical deflection of the specimens was calculated using the effective moment of inertia equation recommended by ACI 318-19 based on the curvature relationships and experimental results of the flexure critical beams. By comparing the experimental and analytical results, it was revealed that the deflection obtained using the ACI equation underestimated the experimental results by up to about 1.6 times when the shear effect was large.
\end{abstract}

Keywords: deflection; shear; flexure; effective moment of inertia; RC beams

\section{Introduction}

Excessive deflection or cracking interferes with the function of reinforced concrete (RC) structures and causes inconvenience for users even if the strength of the structure satisfies safety standards. Therefore, the serviceability of RC structures must be reviewed. Many structural standards, including the current ACI building code [1], are based on the ultimate strength design method. Because the ultimate strength design method uses the ultimate state of the materials in the design, serviceability review for deflection or cracking is recommended.

Deflection, which is one of the serviceability factors that must be considered, should be designed to be within the allowable range recommended by structural standards for the working load conditions. RC structures can crack even under a working load, and the flexural rigidity of the member changes depending on the degree of cracking. In an experimental study that illustrates these characteristics, Branson [2] proposed a relatively simple equation for the effective moment of inertia that uses the relationship between the bending moment at the time of cracking and the subsequent bending moment. This formula was adopted in the ACI building code from 1971 to 2018 and used for calculating the deflection of RC beams [3]. Recently, the equation proposed by Bischoff [4] using a spring model has been applied to ACI 318-19 for the effective moment of inertia.

Since the Branson equation was proposed, many researchers have conducted studies on the deflection of RC beams. Yu and Winter [5] investigated the deflection of RC beams subjected to uniformly distributed loads. They proposed a simplified procedure for calculating the elastic deflection using the moment of inertia of the cracked section and a deflection calculation method that uses the flexural stiffness of uncracked concrete in the tension zone. Grossman [6] discovered that the effective moment of inertia is sensitive to change in moment ratio when the applied moment is small and modified Branson's formula to simplify the calculation of the effective moment of inertia. Rangan [7] proposed an effective moment of inertia obtained by considering the tension reinforcement ratio. 
Al-Shaikh and Al-Zaid [8] studied the variation of the effective moment of inertia under non-uniformly distributed loads in contrast with Branson's formula, which was derived from experimental results under a uniform load. Fikry and Thomas [9] proposed an effective moment of inertia obtained by considering the tension reinforcement ratio and the moment distribution that varies according to the loading patterns to approximate the moment of inertia of the cracked section. Araújo [10] pointed out that the deflection calculated by the ACI method is accurate for short-term loads but inaccurate for long-term loads. Akmaluddin and Thomas [11] modified the equation proposed by Fikry and Thomas using the concrete compressive strength and the shear span of beams as variables.

Bischoff and Scanlon [12] reported that Branson's equation had a larger deviation in members with steel reinforcement ratios of $1 \%$ or less. Scanlon and Bischoff [13] recommended that cracking moment should be reduced to $2 / 3$ in consideration of restraint and the reduction of the tensile strength of concrete during construction. Issal et al. [14] recommended modifying Branson's formula based on flexural tests on the tension reinforcement ratio and load pattern. Kheyroddin and Maleki [15] proposed a new equation of the effective moment of inertia of FRP-steel RC beams using Branson's formula. Bertero and Bertero [16] evaluated the accuracy of Branson and Bischoff equations for the minimum deflection of two-way slabs. Bischoff [17] calculated the deflection of tilt-up concrete wall panels under service load. Bischoff [18] also compared his own formula, adopted in ACI 318-19, with the approaches of Branson and Europe.

The deflection of RC beams is affected not only by bending but also by shear. In particular, it is challenging to calculate deflection analytically because RC beams deform significantly depending on the occurrence and propagation characteristics of cracks, and experimental research and verification are necessary. ACI 318-19 formula proposed by Bischoff was derived from curvature relationships based on flexural theory and tests [18], and it is necessary to verify whether to underestimate the deflection of the beams when the effect of shear increases. However, there are few studies focusing on this aspect. In this study, flexural tests of RC beams were performed with the shear span-to-depth ratio, shear capacity ratio, and tension reinforcement ratio as test variables. Furthermore, the effect of shear on the effective moment of inertia and deflection of RC beams was experimentally evaluated in this study.

\section{Experimental Study}

\subsection{Materials}

Concrete mixture proportion is presented in Table 1. In this study, crushed limestone with a maximum size of $25 \mathrm{~mm}$ and washed sand were used for the coarse and fine aggregates of the concrete, respectively. In this study, ready-mixed concrete from one batch was used to maintain the same quality of the concrete. The slump during concrete placement was measured to be $150 \mathrm{~mm}$. Thirty concrete cylinders with a diameter of $100 \mathrm{~mm}$ and a height of $200 \mathrm{~mm}$ were manufactured and cured in the same environment as beam specimens. The concrete compression test was conducted according to the failure date of the beam specimens. The average concrete compressive strength was measured to be 26.8 MPa with a coefficient of variation (COV) of $10.4 \%$. A typical stress-strain curve of the concrete is shown in Figure 1a.

Table 1. Concrete mixture proportion.

\begin{tabular}{|c|c|c|c|c|c|c|c|c|c|}
\hline \multirow{2}{*}{ Design Strength (MPa) } & \multirow{2}{*}{ W/B (\%) } & \multirow{2}{*}{ S/a (\%) } & \multicolumn{7}{|c|}{ Unit Weight $\left(\mathrm{Kg} / \mathrm{m}^{3}\right)$} \\
\hline & & & W & $\mathrm{C}$ & $\mathrm{S} / \mathrm{P}$ & F/A & $S$ & G & AD \\
\hline 24 & 53.6 & 49.2 & 177 & 221 & 50 & 59 & 871 & 899 & 1.98 \\
\hline
\end{tabular}

Note: $\mathrm{S} / \mathrm{P}=$ blast furnace slag powder, $\mathrm{F} / \mathrm{A}=$ fly ash, and $\mathrm{AD}=$ air-entraining agent. 


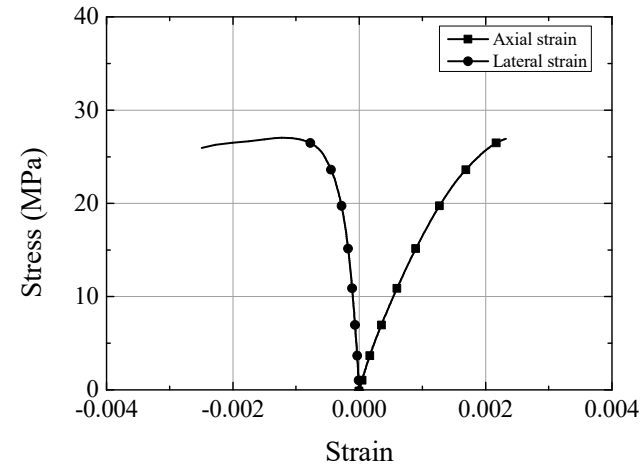

(a)

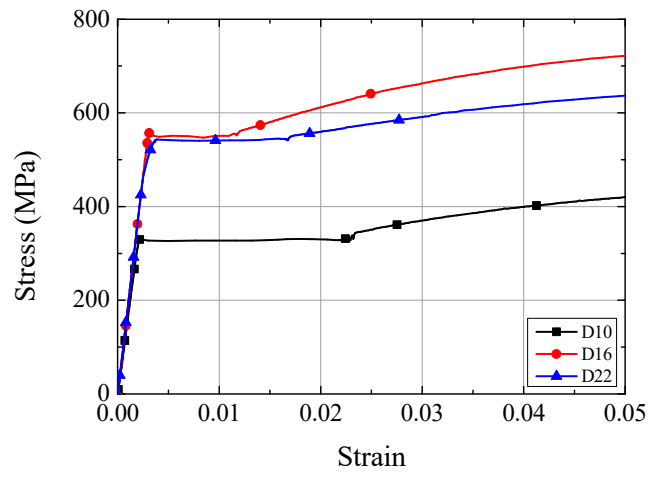

(b)

Figure 1. Stress vs. strain relationships of used materials: (a) concrete; (b) steel bars.

D10 $\left(71.3 \mathrm{~mm}^{2}\right)$, D16 $\left(198.6 \mathrm{~mm}^{2}\right)$, and D22 $\left(387.1 \mathrm{~mm}^{2}\right)$ reinforcing bars were used in this study. Three rebar specimens were tested per type of reinforcing bar. The tensile test of rebar for average yield strength showed that the D10 rebar was $322.0 \mathrm{MPa}$, and D16 and D22 were $546.5 \mathrm{MPa}$ and $543.4 \mathrm{MPa}$, respectively. The COV of the average yield strength of reinforcing bars was within $3.4 \%$. The stress versus strain relationships of rebars are shown in Figure $1 b$. The strength tests of used materials were performed using a universal testing machine (UTM) with a capacity of $1000 \mathrm{kN}$.

\subsection{Test Specimens}

In this study, as shown in Table 2, a total of nine specimens were designed. The crosssection of the specimens was $200 \times 400 \mathrm{~mm}$, and the clear span was planned to be 2250 and $3300 \mathrm{~mm}$. The distance between loading points was $500 \mathrm{~mm}$. The shear span-to-depth ratios were planned to be 2.5 and 4.0. The spacing of shear reinforcement was such that the ratios of the shear strength to the flexural strength of the specimens were 1.1, 1.4, and 1.7. The shear and flexural strengths of specimens were calculated according to the provisions recommended by the ACI building code [19].

Table 2. Details of tested specimens.

\begin{tabular}{|c|c|c|c|c|c|c|c|c|}
\hline \multirow{3}{*}{ Specimens } & \multirow{3}{*}{$\rho-\rho^{\prime}$} & \multirow{3}{*}{$a_{v}(\mathrm{~mm})$} & \multirow{3}{*}{$a_{v} / d$} & \multicolumn{4}{|c|}{ Reinforcing Bars } & \multirow{3}{*}{$\frac{V_{\text {shear }}}{V_{\text {flexure }}}$} \\
\hline & & & & \multirow{2}{*}{ Tension } & \multirow{2}{*}{ Compression } & \multicolumn{2}{|c|}{ Shear } & \\
\hline & & & & & & $s(\mathrm{~mm})$ & $\rho_{w}(\%)$ & \\
\hline B3-2.5a & \multirow{3}{*}{$0.3 \rho_{b}$} & \multirow{3}{*}{875} & \multirow{3}{*}{2.5} & \multirow{3}{*}{$\begin{array}{c}2-\mathrm{D} 22 \\
(\rho=0.0111)\end{array}$} & \multirow{9}{*}{$\begin{array}{c}2-\mathrm{D} 16 \\
(\rho=0.0057)\end{array}$} & D10@160 & 0.45 & 1.1 \\
\hline B3-2.5b & & & & & & D10@115 & 0.62 & 1.4 \\
\hline B3-2.5c & & & & & & D10@90 & 0.79 & 1.6 \\
\hline B6-2.5a & \multirow{6}{*}{$0.6 \rho_{b}$} & \multirow{3}{*}{875} & \multirow{3}{*}{2.5} & \multirow{6}{*}{$\begin{array}{c}3-\mathrm{D} 22 \\
(\rho=0.0166)\end{array}$} & & D10@95 & 0.75 & 1.1 \\
\hline B6-2.5b & & & & & & D10@70 & 1.02 & 1.4 \\
\hline B6-2.5c & & & & & & D10@55 & 1.30 & 1.7 \\
\hline B6-4.0a & & \multirow{3}{*}{1400} & \multirow{3}{*}{4.0} & & & D10@180 & 0.40 & 1.1 \\
\hline B6-4.0b & & & & & & D10@130 & 0.55 & 1.4 \\
\hline B6-4.0c & & & & & & D10@100 & 0.71 & 1.7 \\
\hline
\end{tabular}

Note: $\rho$ and $\rho^{\prime}=$ tension and compression reinforcement ratios, respectively; $\rho_{b}=$ balanced steel ratio for singly reinforced section; $\rho_{w}$ $=$ shear reinforcement ratio; $a_{v}$ and $a_{v} / d=$ shear span and shear span-to-depth ratio, respectively; $s=$ spacing of shear reinforcement; $V_{\text {shear }}$ and $V_{\text {flexure }}=$ shear forces reached at $V_{n}$ and $M_{n}$ calculated using ACI building code; and $V_{n}$ and $M_{n}=$ nominal shear and flexural strengths of specimens, respectively.

Figure 2 shows the details of the specimens. Strain gauges with $5 \mathrm{~mm}$ length and 5\% measuring range for steel were attached to the reinforcing bars to measure the strains of the tension, compression, and shear reinforcing bars, as shown in Figure 2 with red remarks. As shown in Table 2, the test variables were planned to be the shear span-to-depth ratio, 
shear capacity ratio, $V_{\text {shear }} / V_{\text {flexure }}$ in Table 2 , and tension reinforcement ratio to evaluate the effect of shear on the deflection of RC beams subjected to combined bending and shear.

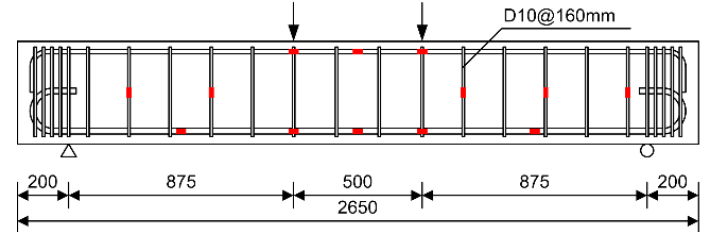

(a)

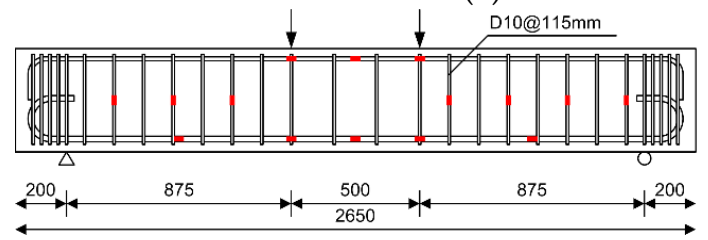

(b)

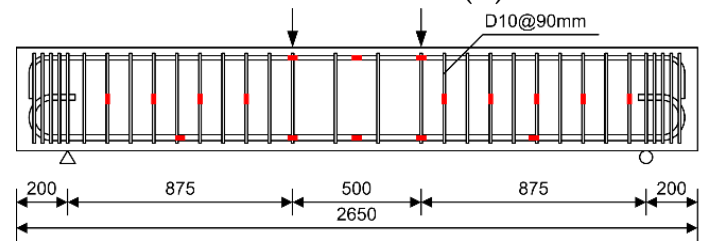

(c)

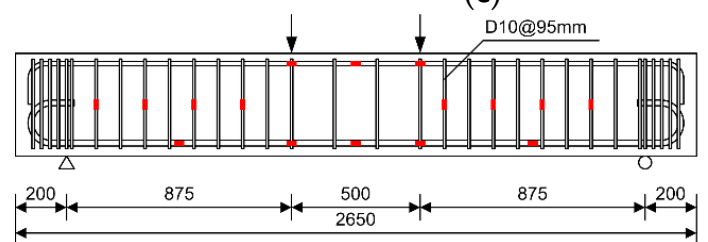

(d)

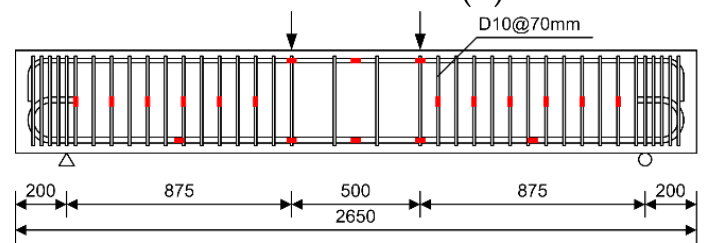

(e)

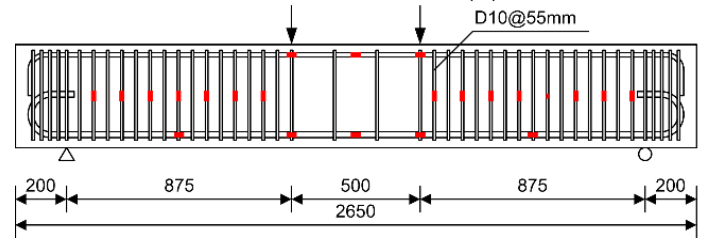

(f)

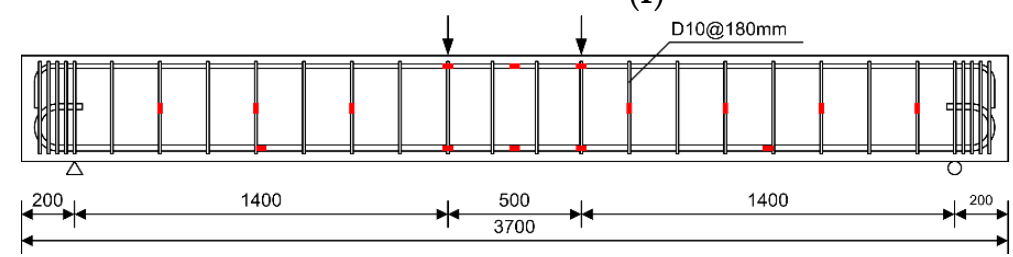

$(\mathrm{g})$
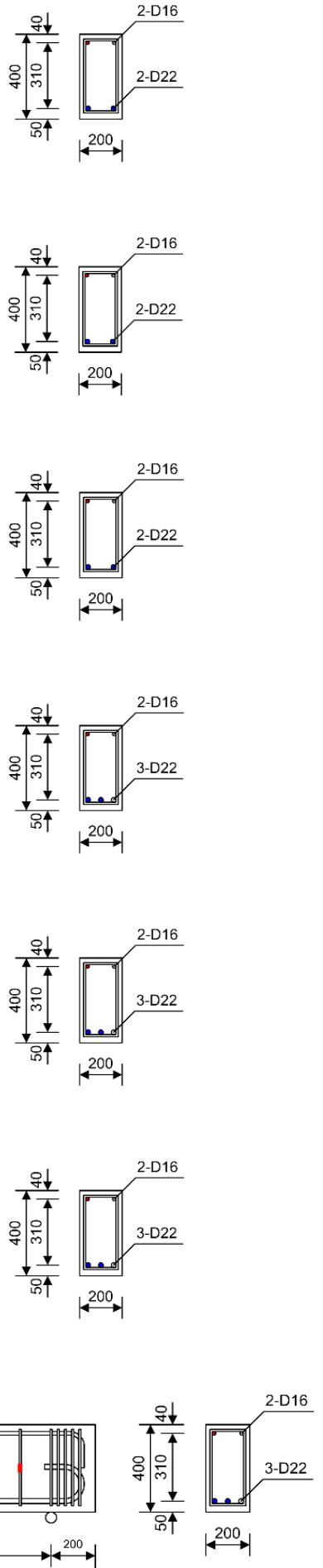

Figure 2. Cont. 

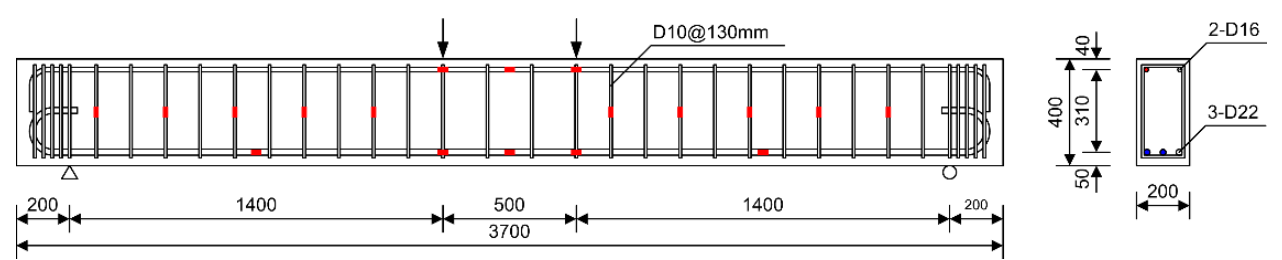

(h)
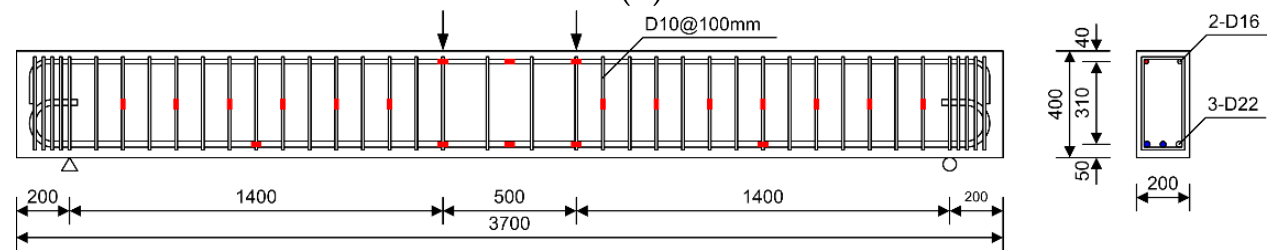

(i)

Figure 2. Details of specimens: (a) B3-2.5a; (b) B3-2.5b; (c) B3-2.5c; (d) B6-2.5a; (e) B6-2.5b; (f) B6-2.5c; (g) B6-4.0a; (h) B6-4.0b; (i) B6-4.0c (unit: mm).

\subsection{Test Setup and Loading Procedure}

The test setup of a typical specimen is illustrated in Figure 3. A static monotonic loading test was done on the specimen using a UTM with a capacity of $2000 \mathrm{kN}$. The experiment was controlled by the continuous deformation and terminated when the load dropped to less than $85 \%$ of the observed peak load. As shown in Figure 3, linear variable differential transducers (LVDTs) with $100 \mathrm{~mm}$ capacity were installed at the opposite side of the top loading points and the mid-span point of the specimens to measure deflections. In addition, as shown in Figure 3, strain gauges with $60 \mathrm{~mm}$ length and 2\% measuring range for concrete were attached at positions 0,20 , and $40 \mathrm{~mm}$ away from the extreme compression fiber to measure the compressive strain of the specimens.

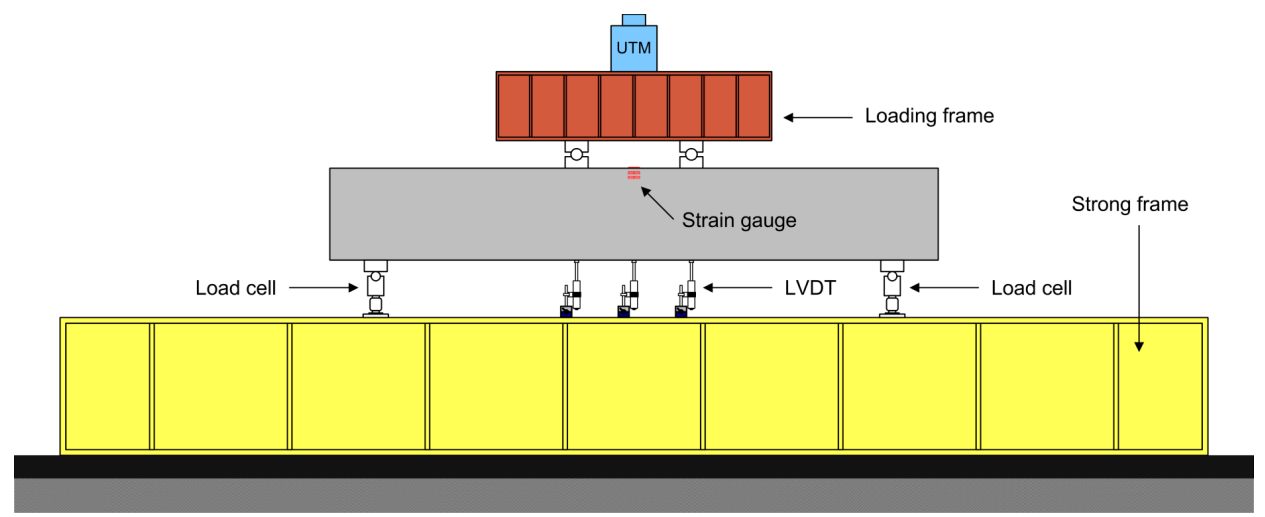

Figure 3. Test setup of a typical specimen.

\section{Experimental Results}

\subsection{Load vs. Deflection Relationships}

Figure 4 shows the load-deflection relationships of the specimens measured in this test. The experimental results of the load and deflection at the principal states are shown in Table 3. As shown in Figure 4, all specimens exhibited a flexural failure mode in which the final fracture occurred owing to the crushing of the compressed concrete after flexural yielding. In addition, because the amount of shear reinforcement in all specimens was higher than that recommended in the shear provisions of the ACI building code, the shear steel bars did not yield until the end of the experiment. 


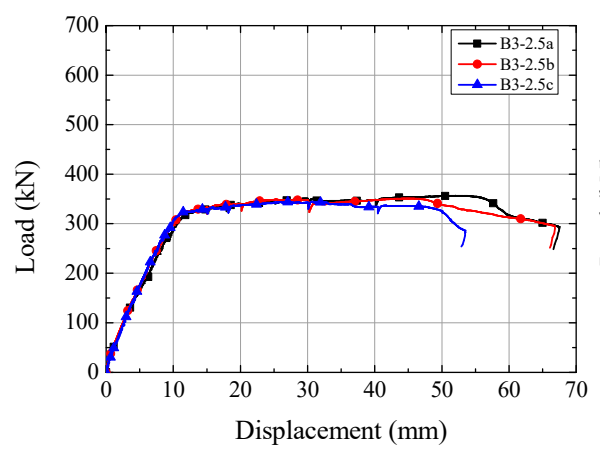

(a)

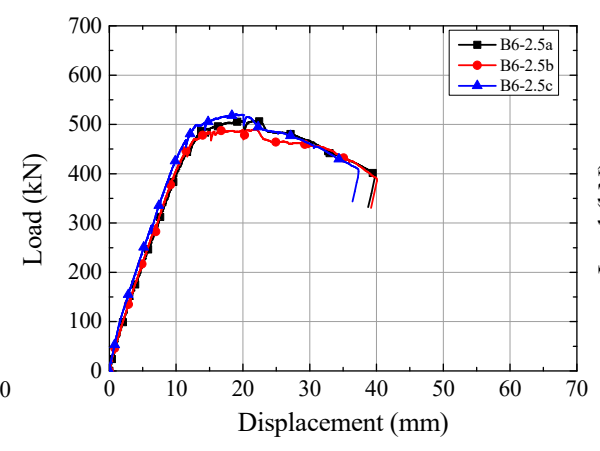

(b)

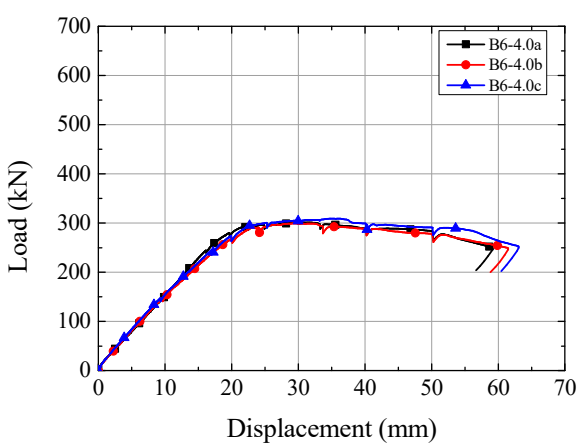

(c)

Figure 4. Load vs. displacement relationships of tested specimens: (a) B3-2.5 Series; (b) B6-2.5 Series; (c) B6-4.0 Series.

Table 3. Load and deflection capacities of specimens obtained from this study.

\begin{tabular}{|c|c|c|c|c|c|c|c|c|c|c|}
\hline \multirow[b]{2}{*}{ Specimens } & \multicolumn{2}{|c|}{ At First Crack } & \multicolumn{6}{|c|}{ At First Flexural Yield } & \multicolumn{2}{|c|}{ At Peak Load } \\
\hline & $\begin{array}{c}P_{c r} \\
(\mathbf{k N})\end{array}$ & $\begin{array}{c}\Delta_{c r} \\
(\mathrm{~mm})\end{array}$ & $\begin{array}{c}P_{y} \\
(\mathbf{k N})\end{array}$ & $\begin{array}{c}\Delta_{y, L} \\
(\mathrm{~mm})\end{array}$ & $\begin{array}{c}\Delta_{y, G} \\
(\mathbf{m m})\end{array}$ & $\frac{\Delta_{y, L}}{\Delta_{y, G}}$ & $\frac{\Delta_{y, L}}{\Delta_{y, \text { ana. }}}$ & $\frac{\Delta_{y, G}}{\Delta_{y, a n a .}}$ & $\begin{array}{c}P_{u} \\
(\mathrm{kN})\end{array}$ & $\begin{array}{c}\Delta_{u} \\
(\mathrm{~mm})\end{array}$ \\
\hline B3-2.5a & 31.2 & 0.51 & 285.3 & 9.9 & 6.1 & 1.62 & 1.44 & 0.89 & 356.6 & 52.0 \\
\hline B3-2.5b & 33.3 & 0.57 & 299.7 & 9.8 & 6.9 & 1.42 & 1.43 & 1.01 & 350.7 & 44.7 \\
\hline B3-2.5c & 31.2 & 0.62 & 296.1 & 9.5 & 6.6 & 1.44 & 1.38 & 0.96 & 344.4 & 30.5 \\
\hline B6-2.5a & 30.4 & 0.52 & 451.6 & 11.9 & 7.6 & 1.57 & 1.56 & 1.00 & 507.7 & 22.1 \\
\hline B6-2.5b & 37.9 & 0.65 & 446.8 & 11.5 & 7.7 & 1.49 & 1.51 & 1.01 & 489.8 & 21.9 \\
\hline B6-2.5c & 37.4 & 0.54 & 467.0 & 11.4 & 8.0 & 1.43 & 1.49 & 1.05 & 520.2 & 19.0 \\
\hline B6-4.0a & 25.0 & 1.17 & 275.1 & 19.8 & 14.7 & 1.35 & 1.27 & 0.94 & 301.3 & 30.4 \\
\hline B6-4.0b & 24.8 & 1.18 & 268.7 & 20.1 & 16.1 & 1.25 & 1.29 & 1.03 & 299.1 & 29.4 \\
\hline \multirow[t]{3}{*}{ B6-4.0c } & 24.9 & 1.13 & 274.1 & 19.9 & 14.9 & 1.34 & 1.27 & 0.95 & 308.9 & 34.9 \\
\hline & & & & & Mean & 1.43 & 1.40 & 0.98 & - & - \\
\hline & & & & & $\operatorname{COV}(\%)$ & 8.13 & 7.75 & 5.08 & - & - \\
\hline
\end{tabular}

Note: $P_{c r}, P_{y}$, and $P_{u}=$ applied loads at first cracking, first yielding, and peak load, respectively, $\Delta_{c r}, \Delta_{y, L}$, and $\Delta_{u}=$ measured deflections using LVDT installed on the mid-span of specimens at first cracking, first yielding, and peak load, respectively, $\Delta_{y, G}=$ deflection obtained using strain gauges attached on the mid-span of specimens, $\Delta_{y, a n a}$. analytical deflection using ACI equation.

As shown in Table 3, the load and deflection at the first flexural yielding of the B32.5 series specimens with the tension reinforcement ratio of $0.3 \rho_{b}\left(=\rho-\rho^{\prime}\right)$ were lower than those of the B6-2.5 series specimens with the ratio of $0.6 \rho_{b}$, while the deflection at peak load was larger. The B6-2.5 and B6-4.0 series specimens were identical except for the shear span-to-depth ratio. As shown in Figure 4, as the shear span-to-depth ratio increased from 2.5 to 4.0, the flexural strength was significantly reduced while the ductile behavior was remarkable. However, the shear capacity ratio had little effect on the loaddeflection relationships.

\subsection{Crack Patterns}

Figure 5 shows the crack patterns at the peak load for each specimen. The crack patterns were sketched after pictures taken during the test. In all specimens, flexural cracks first occurred at the mid-span of the specimens, and the cracks progressed to both ends as the load increased. After the peak load, concrete crushing occurred between the loading points, exhibiting a flexural failure mode. 


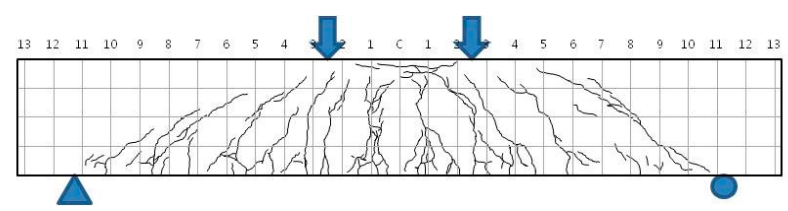

(a)

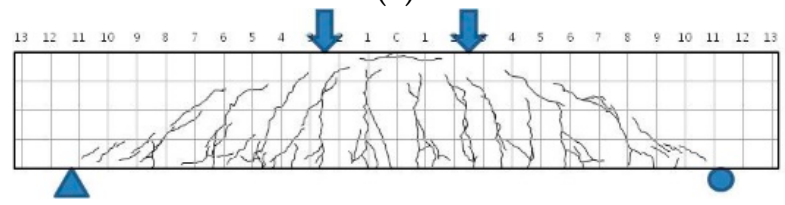

(b)

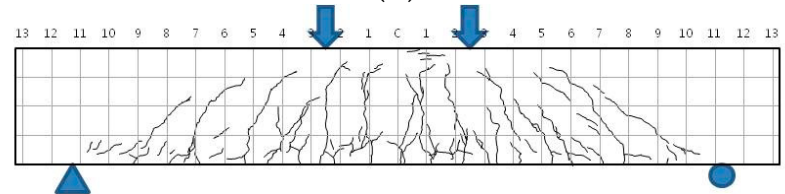

(c)

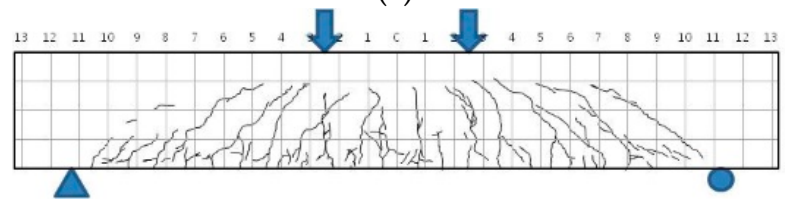

(d)

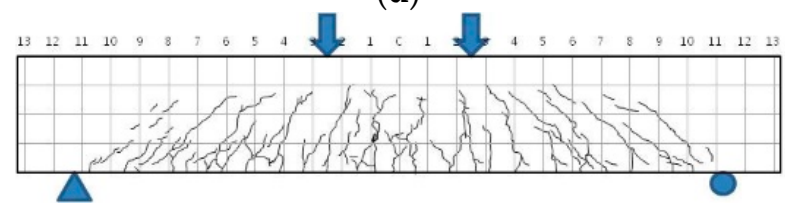

(e)

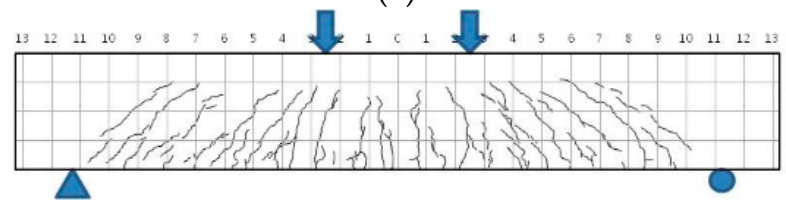

$(\mathbf{f})$

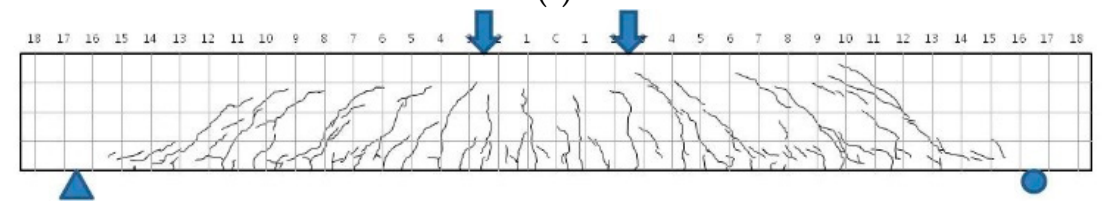

(g)

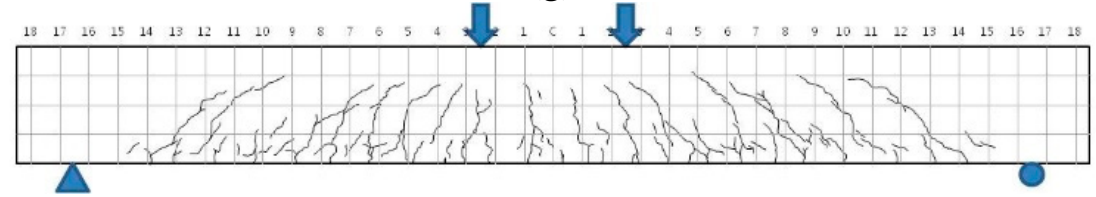

(h)

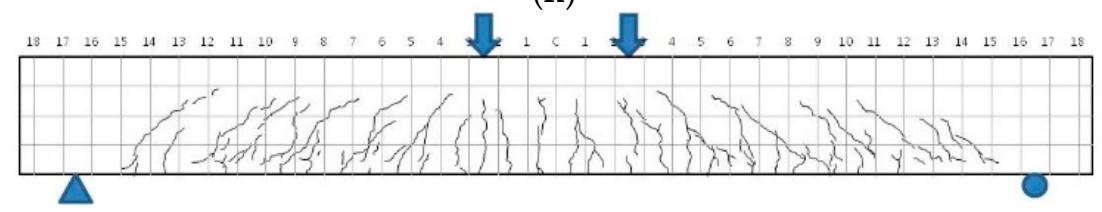

(i)

Figure 5. Crack patterns of specimens at peak load: (a) B3-2.5a; (b) B3-2.5b; (c) B3-2.5c; (d) B6-2.5a; (e) B6-2.5b; (f) B6-2.5c; (g) B6-4.0a; (h) B6-4.0b; (i) B6-4.0c.

From Figure 5, it is evident that the B3-2.5 series specimens, which have a lower tension reinforcement ratio than the B6-2.5 series specimens, have more progressed flexural 
and shear cracks to the top. This is because the lower the tension reinforcement ratio, the higher the position of the neutral axis. In addition, the B3-2.5 series specimens had a smaller number of shear cracks and a wider crack spacing than the B6-2.5 series specimens because the shear stress applied to the specimen was smaller, owing to its low load-resistance capacity for flexure.

Because the B6-4.0 series specimens had a higher shear-to-span ratio than the B6-2.5 series specimens, flexure was remarkably more dominant than shear. The cracks also illustrated these characteristics, and as illustrated in Figure 5, the crack spacing of the B6-4.0 series specimens was wider than that of the B6-2.5 series specimens. In the B6-2.5 series specimens with relatively large shear effect, as the spacing of the shear reinforcing bars narrowed, the shear crack spacing gradually narrowed. However, for the other series specimens, the effect of the spacing of the shear reinforcement on the cracks was not founded.

\section{Discussions}

\subsection{Flexural Strength at First Flexural Yield and Ultimate State}

Table 4 compares the experimental and analysis results of the flexural strength at the first flexural yielding and peak load of each specimen. The experimental result of the yield moment is the applied moment when the strain gauge attached to the tension reinforcing bars first reaches the yield strain, as measured in Figure 1b. In addition, the experimental results of the ultimate moment were taken as the moment applied to the specimens at the peak load. The yield and ultimate moment of specimens, $M_{y}$ and $M_{u}$, can be obtained analytically from the following equations using the equilibrium and compatibility conditions [20]:

$$
\begin{aligned}
& M_{y}=0.5 f_{c} b k d\left(d-\frac{k d}{3}\right)+A_{s}^{\prime} f_{s}^{\prime}\left(d-d^{\prime}\right) \\
& M_{u}=0.85 f_{c k} a b\left(d-\frac{a}{2}\right)+A_{s}^{\prime} f_{s}^{\prime}\left(d-d^{\prime}\right)
\end{aligned}
$$

where $f_{c}$ is the compressive stress of concrete, $b$ is the beam width, $k d$ is the depth of the neutral axis at flexural yielding, $d$ is the depth of the beam, $a$ is the depth of the equivalent stress block, $f_{c k}$ is the design strength of the concrete, $A_{s}^{\prime}$ and $f_{s}^{\prime}$ are the amount and stress of the compression reinforcement, respectively, and $d^{\prime}$ is the distance between the centroid of the compression reinforcement and the extreme compression fiber.

\begin{tabular}{|c|c|c|c|c|}
\hline \multirow[b]{2}{*}{ Specimens } & \multicolumn{2}{|c|}{ Experimental } & \multicolumn{2}{|c|}{ Experimental/Analytical } \\
\hline & $\begin{array}{l}M_{y, \text { exp. }} \\
(\mathbf{k N m})\end{array}$ & $\begin{array}{l}M_{u, \exp } \\
(\mathrm{kNm})\end{array}$ & $\frac{M_{y, \text { exp. }}}{M_{y, \text { ana. }}}$ & $\frac{M_{u, \text { exp. }}}{M_{u, \text { ana. }}}$ \\
\hline B3-2.5a & 124.8 & 156.0 & 0.94 & 1.18 \\
\hline B3-2.5b & 131.1 & 153.4 & 0.99 & 1.16 \\
\hline B3-2.5c & 129.5 & 150.7 & 0.97 & 1.14 \\
\hline B6-2.5a & 197.6 & 222.1 & 1.01 & 1.17 \\
\hline B6-2.5b & 195.5 & 214.3 & 1.00 & 1.13 \\
\hline B6-2.5c & 204.3 & 227.6 & 1.05 & 1.20 \\
\hline B6-4.0a & 192.6 & 210.9 & 0.99 & 1.11 \\
\hline B6-4.0b & 188.1 & 209.4 & 0.96 & 1.10 \\
\hline \multirow[t]{3}{*}{ B6-4.0c } & 191.9 & 216.2 & 0.98 & 1.14 \\
\hline & & Mean & 0.99 & 1.15 \\
\hline & & $\operatorname{COV}(\%)$ & 3.06 & 2.78 \\
\hline
\end{tabular}

Table 4. Comparison of experimental and analytical results for flexural moment.

As shown in Table 4, the ratios of the analytical results to the experimental results of the yield moment were an average of 0.99 and the COV of $3.06 \%$, indicating that the analytical results predicted the experimental results accurately. The ratio between the 
experimental and analysis results for the ultimate moment was 1.15 on average and the COV was $2.78 \%$, which was found to sufficiently exceed the flexural strength required by the ACI building code.

\subsection{Effective Moment of Inertia}

The experimental result of the effective moment of inertia $I_{e, \text { exp. }}$ was obtained by using the following equation based on the geometrical conditions and general elastic theory for the deflection measured from the LVDT installed at the mid-span of the specimens:

$$
I_{e, \exp .}=\frac{M_{a}}{24 E_{c} \Delta}\left(3 l^{2}-4 a_{v}^{2}\right)
$$

where $M_{a}$ is the applied moment at which the deflection is calculated, $E_{c}$ is the elastic modulus of the concrete, $\Delta$ is the deflection of the beam, $l$ is the clear span of the beam, and $a_{v}$ is the shear span of the beam. For the analytical result of the effective moment of inertia, the following formula proposed by ACI 318-19 [1] was used:

$$
I_{e}=\frac{I_{c r}}{1-\left(\frac{(2 / 3) M_{c r}}{M_{a}}\right)^{2}\left(1-\frac{I_{c r}}{I_{g}}\right)}
$$

for $M_{a}>(2 / 3) M_{c r}, I_{e}=I_{g}$ for $M_{a} \leq(2 / 3) M_{c r}, I_{c r}$ is for the cracked section transformed to concrete, $I_{g}$ is for the gross concrete section about the centroidal axis, $M_{c r}$ is the cracking moment.

Figure 6 shows the comparison between the experimental and analytical results of the effective moment of inertia. After the crack occurred, the analytical and experimental results had similar curves. As shown in Figure 6, as the shear span-to-depth ratio decreased or the tension reinforcement ratio increased, the effect of shear increased and the difference between the experimental and analytical results increased. In other words, comparing the experimental and analytical results for the $I_{e}$ value at the yield moment, the difference for B6-4.0 series specimens subjected to relatively low shear stress was about 1.3 times, while the difference for B3-2.5 and B6-2.5 series specimens having relatively high shear stress was about 1.4 and 1.5 times.

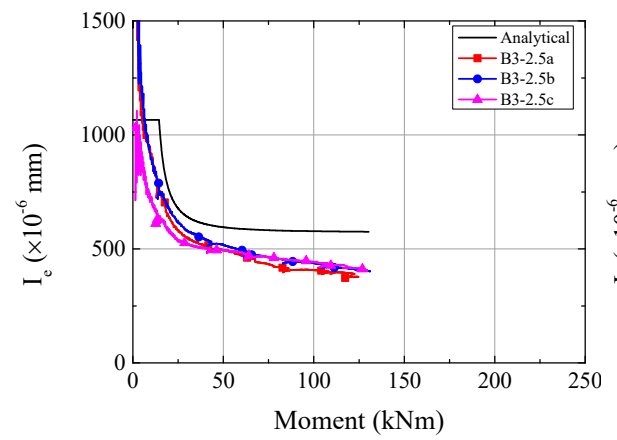

(a)

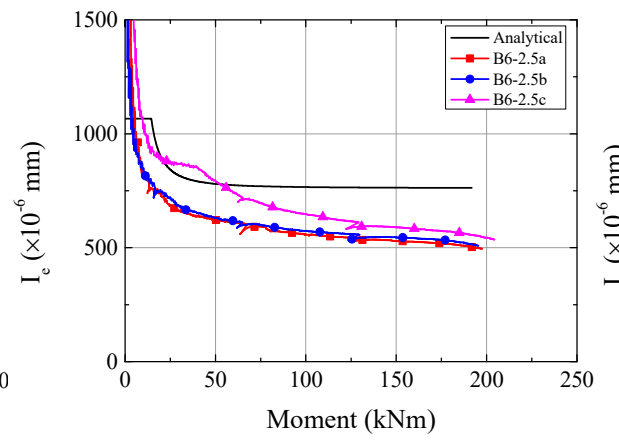

(b)

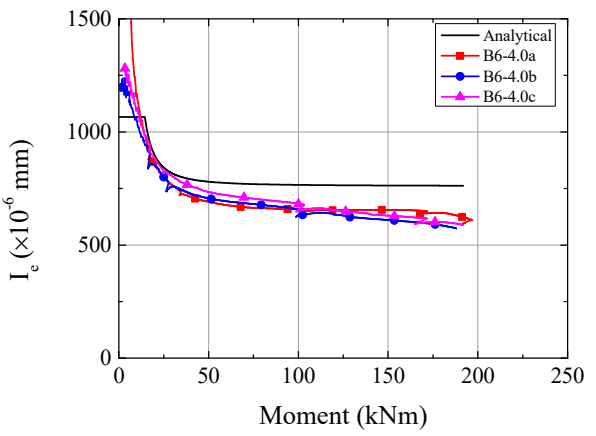

(c)

Figure 6. Moment versus effective moment of inertia relationships: (a) B3-2.5 series; (b) B6-2.5 series; (c) B6-4.0 series.

As shown in Figure 6, for each series specimens, no significant difference was observed in most of the specimens for the shear capacity ratio. Although Specimen B6-2.5c showed almost no difference between the experimental results and the analysis results in the initial working load stage after cracking moment, as the load increased with the yield moment, it showed almost similar differences with Specimens B6-2.5a and B6-2.5b. 


\subsection{Deflection}

Figure 7 compares the experimental and analytical results of the load-deflection relationships. It is noted that the analytical results were evaluated up to the yield value, while the experimental results expand to the whole measured range. The analytical results for the deflection in Figure 7 were obtained by substituting the effective moment of inertia obtained from Equation (4) into the following equation:

$$
\Delta_{\text {ana. }}=\frac{M_{a}}{24 E_{c} I_{e, a n a .}}\left(3 l^{2}-4 a_{v}^{2}\right)
$$

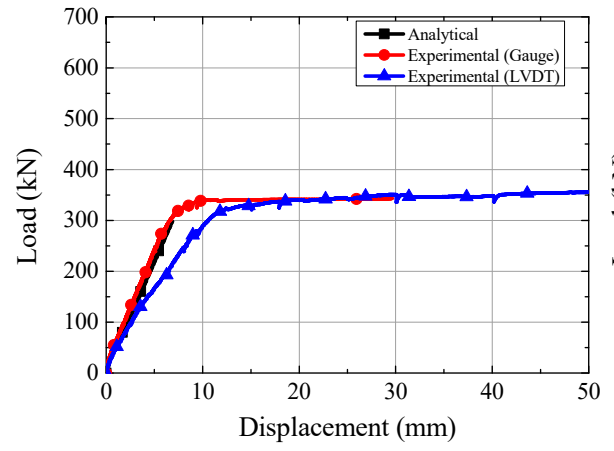

(a)

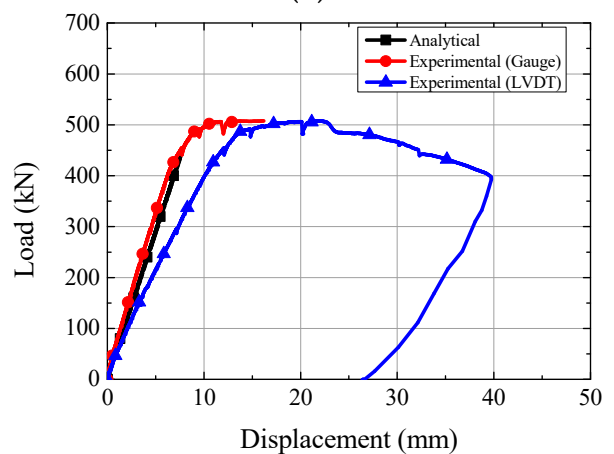

(d)

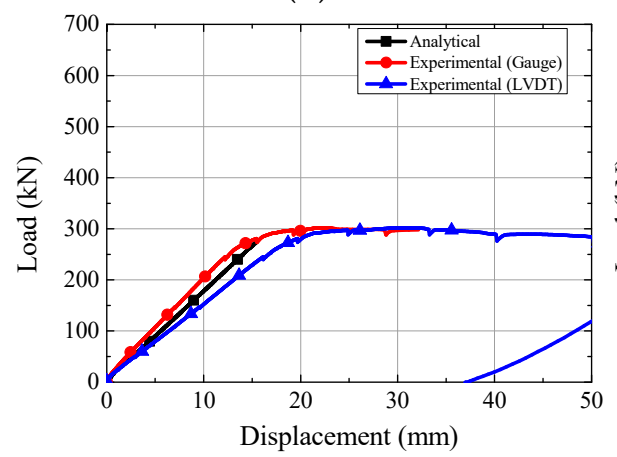

(g)

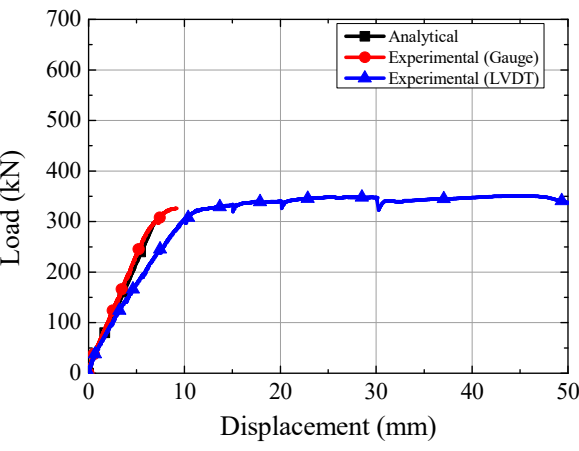

(b)

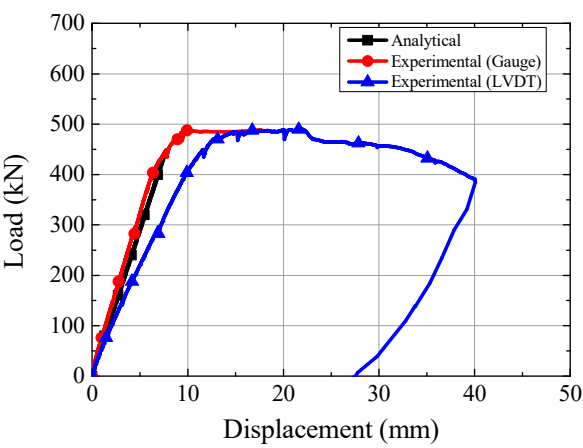

(e)

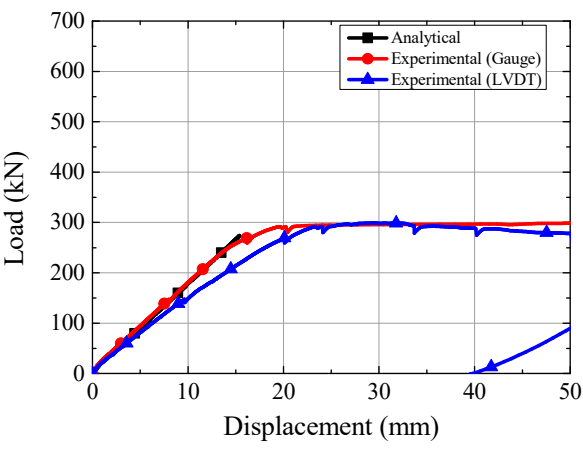

(h)

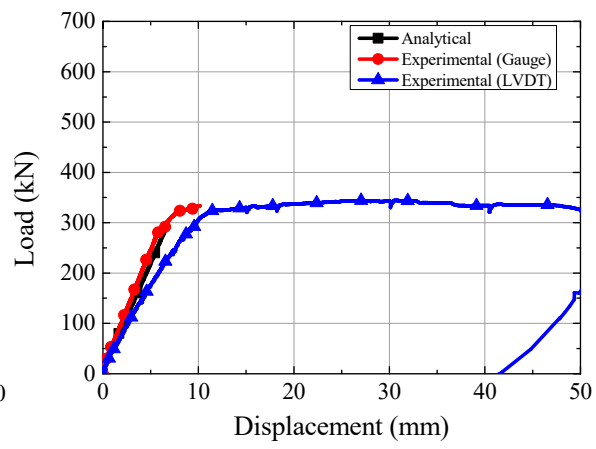

(c)

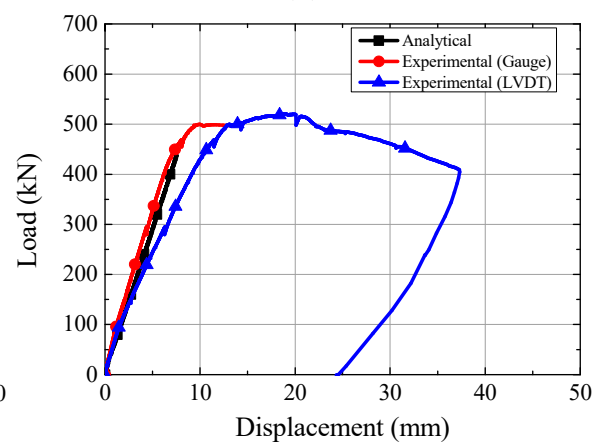

(f)

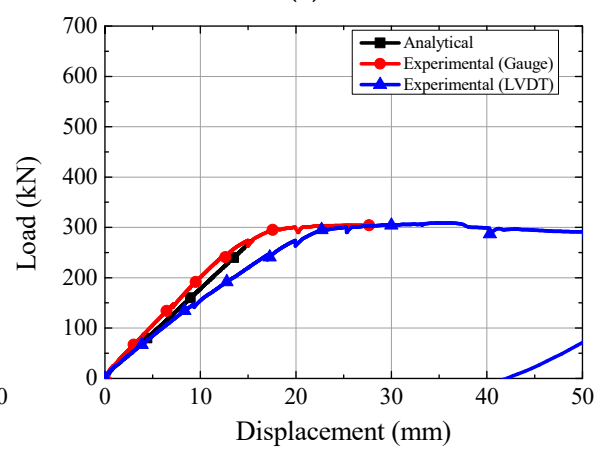

(i)

Figure 7. Comparison of experimental and analytical results: (a) B3-2.5a; (b) B3-2.5b; (c) B3-2.5c; (d) B6-2.5a; (e) B6-2.5b; (f) B6-2.5c; (g) B6-4.0a; (h) B6-4.0b; (i) B6-4.0c.

The experimental deflections were grouped into two categories: (1) deflection measured directly from the LVDT at the mid-span of the specimen and (2) deflection obtained using the experimental curvature at the mid-span of the specimens. The experimental 
curvature $\varphi_{\text {exp. }}$ was obtained from the values of the strain gauges attached to the tension reinforcing bar and the extreme compression fiber of concrete as follows:

$$
\varphi_{\text {exp. }}=\frac{1}{R}=\frac{\varepsilon_{c}+\varepsilon_{s}}{d}
$$

where $R$ is the radius of curvature, $\varepsilon_{\mathcal{C}}$ is the concrete strain of the extreme compression fiber, and $\varepsilon_{S}$ is the strain of the tension reinforcing bar.

The curvature obtained from Equation (6) can be substituted into the following equation to obtain the change in the effective moment of inertia for the entire loading history:

$$
I_{e, \varphi}=\frac{M_{a}}{E_{c} \varphi_{\exp }}
$$

The deflection can be obtained by substituting the effective moment of inertia obtained from Equation (7) into the following equation:

$$
\Delta_{e x p, G}=\frac{M_{a}}{24 E_{c} I_{e, \varphi}}\left(3 l^{2}-4 a_{v}^{2}\right)
$$

Substituting Equation (7) into Equation (8), the equation for $\Delta_{\exp , G}$ is only dependent on the curvature $\varphi_{\text {exp. }}$. Since the experimental curvature was obtained using the value of strain gauges at mid-span of the specimens, Equation (8) reflects only the flexural deformation. Regarding the deflection at the first yielding of the tension reinforcement, Table 3 shows the experimental deflections $\Delta_{y, L}$ and $\Delta_{y, G}$ obtained from LVDT and Equation (8), and the analytical deflection $\Delta_{y, a n a}$. calculated using ACI 318-19 formula. It is noted that $\Delta_{y, G}$ is the deflection due to flexural deformation, and $\Delta_{y, L}$ is the deflection due to combined bending and shear deformations. As shown in Table $3, \Delta_{y, L} / \Delta_{y, G}$ was approximately 1.5 for the B3-2.5 series and B6-2.5 series specimens with a small shear span-to-depth ratio, which means that the deflection due to shear deformation is approximately $50 \%$ of the deflection due to flexural deformation.

As shown in Figure 7, the analytical result obtained from ACI equation had similar behavior to the load-deflection relationship obtained from the strain gauges attached to the pure bending region. In addition, from Table 3, it can be confirmed that the ratio of experimental and analytical results for deflection $\Delta_{y, G} / \Delta_{y, \text { ana. }}$ are in agreement, with an average of 0.98 and a COV of $5.08 \%$ for all specimens. However, the analytical results obtained using ACI equation significantly differed from the load-deflection relationship measured directly from the LVDT.

When the shear stress acting on the shear span of specimens increased, that is, the lower the shear span ratio or the higher the tension reinforcement ratio, the difference between the experimental and analytical results also increased. This is because the deflection measured directly by the LVDT is not only due to flexure, but also due to shear deformation. For example, as shown in Table 3 , for the B6-4.0 series specimens, $\Delta_{y, L} / \Delta_{y, \text { ana }}$ is 1.28 on average, whereas for the B3-2.5 series and B6-2.5 series specimens, the averages are 1.42 and 1.52, respectively, indicating that the accuracy is significantly decreased. Figure 7 and Table 3 shows that no difference in deflection according to the shear capacity ratio was found when the amount of shear reinforcement required by the shear provisions of the ACI building code is satisfied. From comparing the experimental and theoretical results, the effective moment of inertia obtained using ACI equation needs to be corrected considering the shear deformation caused by shear stress acting on the shear span of the specimens.

\section{Conclusions}

In this study, an experiment was performed to evaluate the effect of shear on the deflection of RC beams subjected to combined bending and shear. As a result, the following conclusions were drawn: 
(1) From flexural tests of RC beams with tension reinforcement ratios of $0.3 \rho_{b}$ and $0.6 \rho_{b}$ and shear span-to-depth ratios of 2.5 and 4.0, when the amount of shear reinforcement recommended in the ACI code was satisfied, no additional deflection due to the change in the shear capacity ratio was observed.

(2) When the shear span-to-depth ratio was small or the tension reinforcement ratio was high, it was observed that the number of inclined shear cracks increased and their spacing narrowed because a relatively large shear force was applied to the shear span of the specimens.

(3) From the moment versus effective moment of inertia relationships, it was confirmed that the accuracy of ACI 318-19 formula decreased as the effect of shear increased. In other words, when the shear span-to-depth ratio was low or the tension reinforcement ratio was high, the difference between the analytical results using ACI equation and the experimental results obtained from LVDT combined shear-bending component increased.

(4) The deflection at the yield moment obtained using ACI equation almost coincided with the deflection obtained using the curvature measured in the pure bending region, regardless of the shear span-to-depth ratio and tension reinforcement ratio of the specimens, with an average of 1.0. On the other hand, the ACI equation underestimated the experimental results measured by LVDT combined shear-bending component by a maximum of 1.6 times. This is because the ACI equation does not consider the effect of shear on deflection of RC beams.

\begin{abstract}
Author Contributions: S.-W.K., D.-S.H. and K.-H.K. conceived and performed the experiments and analyzed the data and wrote the paper. All authors have read and agreed to the published version of the manuscript.

Funding: This work was supported by the Priority Research Centers Program through the National Research Foundation of Korea (NRF) founded by the Ministry of Education (2019R1A6A1A03032988); this research was supported by Basic Science Research Program through the National Research Foundation of Korea (NRF) founded by the Ministry of Education (2018R1A2B3001656).
\end{abstract}

Institutional Review Board Statement: Not applicable.

Informed Consent Statement: Not applicable.

Data Availability Statement: Not applicable.

Conflicts of Interest: The authors declare no conflict of interest.

\title{
References
}

1. ACI Committee 318. Building Code Requirements for Structural Concrete (ACI 318-19) and Commentary (ACI 318R-19); American Concrete Institute: Farmington Hills, MI, USA, 2019; 623p.

2. Branson, D.E. Instantaneous and Time-Dependent Deflections on Simple and Continuous Reinforced Concrete Beams; HPR Report No. 7, Part 1; Alabama Highway Department, Bureau of Public Roads: Montgomery, AL, USA, 1965; pp. 1-78.

3. Mancuso, C.; Bartlett, F.M. ACI 318-14 criteria for computing instantaneous deflections. ACI Struct. J. 2017, 114, 1299-1310. [CrossRef]

4. Bischoff, P.H. Reevaluation of deflection prediction for concrete beams reinforced with steel and fiber-reinforced polymer bars. J. Struct. Eng. 2005, 131, 752-767. [CrossRef]

5. Yu, W.-W.; Winter, G. Instantaneous and long-time deflections of reinforced concrete beams under working loads. ACI J. Proc. 1960, 57, 29-50.

6. Grossman, J.S. Simplified computations for effective moment of inertia Ie and minimum thickness to avoid deflection computations. ACI J. Proc. 1981, 78, 423-434.

7. Rangan, B.V. Control of beam deflections by allowable span-depth ratios. ACI J. Proc. 1982, 79, 372-377.

8. Al-Shaikh, A.H.; Al-Zaid, R.Z. Effect of reinforcement ratio on the effective moment of inertia of reinforced concrete beams. ACI Struct. J. 1993, 90, 144-149.

9. Fikry, A.M.; Thomas, C. Development of a model for the effective moment of inertia of one-way reinforced concrete elements. ACI Struct. J. 1998, 95, 444-455.

10. Araújo, J.M. Improvement of the ACI method for calculation of deflections of reinforced concrete beams. Theory Pract. Civ. Eng. 2005, 7, 49-60. 
11. Akmaluddin, A.; Thomas, C. Experimental verification of effective moment of inertia used in the calculation of reinforced concrete beam deflection. Int. Civ. Eng. Conf. 2006, 89-98.

12. Bischoff, P.H.; Scanlon, A. Effective moment of inertia for calculating deflections of concrete members containing steel reinforcement and fiber-reinforced polymer reinforcement. ACI Struct. J. 2007, 104, 68-75.

13. Scanlon, A.; Bischoff, P.H. Shrinkage restraint and loading history effects on deflections of flexural members. ACI Struct. J. 2008 105, 498-506.

14. Issa, M.S.; Mahmoud, M.R.; Torkey, A.M.; Mostafa, M.T. Effective moment of inertia of reinforced medium strength concrete beams. HBRC J. 2009, 5, 47-58.

15. Kheyroddin, A.; Maleki, F. Prediction of effective moment of inertia for hybrid FRP-steel reinforced concrete beams using the genetic algorithm. Numer. Methods Civ. Eng. 2017, 2, 15-23.

16. Bertero, R.; Bertero, A. Statistical evaluation of minimum thickness provisions for slab deflection control. ACI Struct. J. 2018, 115, 1659-1670. [CrossRef]

17. Bischoff, P.H. Service load deflection of tilt-up concrete wall panels. Can. J. Civil Eng. 2018, 45, 684-689. [CrossRef]

18. Bischoff, P.H. Comparison of existing approaches for computing deflection of reinforced concrete. ACI Struct. J. 2020, 117, 231-240. [CrossRef]

19. ACI Committee 318. Building Code Requirements for Structural Concrete (ACI 318M-14) and Commentary (ACI 318RM-14); American Concrete Institute: Farmington Hills, MI, USA, 2015; 519p.

20. Park, R.; Paulay, T. Reinforced Concrete Structures; Wiley: New York, NY, USA, 1975; 769p. 